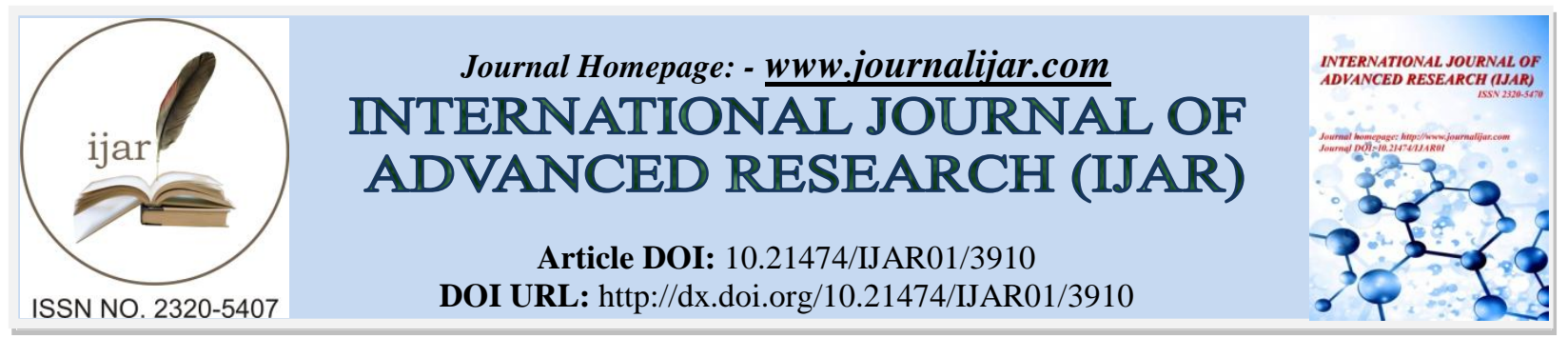

RESEARCH ARTICLE

\title{
A RARE CASE: COMPLICATED LARGE CYSTIC LYMPHANGIOMA AT UNUSUAL SITE RETROPERITONEALLY IN PELVIS AND THIGH.
}

\author{
Preetam $^{1}$, Deepika Meena ${ }^{2}$, Deepak Meena ${ }^{3}$, Manish Kumar Meena ${ }^{4}$ and ${ }^{*}$ G L Meena ${ }^{1}$. \\ 1. Department of Radiodiagnosis, SP Medical College \& Associate Group of PBM Hospitals, Bikaner. \\ 2. Rajasthan Dental College Jaipur. \\ 3. Mahtama Gandhi Dental College Jaipur. \\ 4. S.N. Medical College, Jodhpur.
}

\section{Manuscript Info}

(..........................

Manuscript History

Received: 09 February 2017

Final Accepted: 11 March 2017

Published: April 2017

Key words:-

Mesenteric Cyst, Retroperitoneal Cyst,

Ovarian Cyst, Ileocaecal.

\section{Abstract}

The Retroperitoneal cysts are very rare, and most of the time they are discovered incidentally. Retroperitoneal cysts are uncommon, with an estimated incidence of 1 in 250,000. A Forty year old female presented with complaints of pain for six months with history of loss of appetite and history of weight loss. She was a known Diabetes mellitus and Bronchial asthma on treatment. Per abdomen examination revealed soft, tender without any mass palpable in the right lower abdomen. All basic investigations were normal.

Copy Right, IJAR, 2017,. All rights reserved.

\section{Introduction:-}

Cystic lymphangioma is a rare malformation characterized by cystic structure deriving from detachment of lymph sacs from venous drainage systems ${ }^{1}$. The cystic variant of lymphangioma is included in the general classification of lymphangiomas according to Landing and Farber ${ }^{2}$ enclosing the capillary and venous variant, characterized respectively by dilatation of capillary and sinusoidal lymphatic vessels (the latter with continued growth of the stromal component) which remain connected to the lymphatic network; The cystic variant instead is unconnected with the lymphatic network, characterized by several spaces filled with proteinaceous and chylous material which contains lymphocytes and sometimes red blood cells ${ }^{3}$. Complications arising from non-surgical resection include haemorrhages and infections ${ }^{4}$.

\section{Case report:-}

A 16 yr old girl presented with gradually inceasing size soft tissue swelling in right thigh. There was no h/o of trauma ,fever at local site.Clinical examinaton revealed a slight tender soft compressible swelling .

Plain X-rays,USG, CT Angiography and contast enhanced MRI was perfomed.

Plain pelvis AP view shows soft tissue swelling at anteromedial rt thigh. No abnormal lucency or calcification seen. Underlying bones appear normal.

Corresponding Author:- G L Meena.

Address:- Department of Radiodiagnosis, SP Medical College \& Associate Group of PBM Hospitals, Bikaner. 

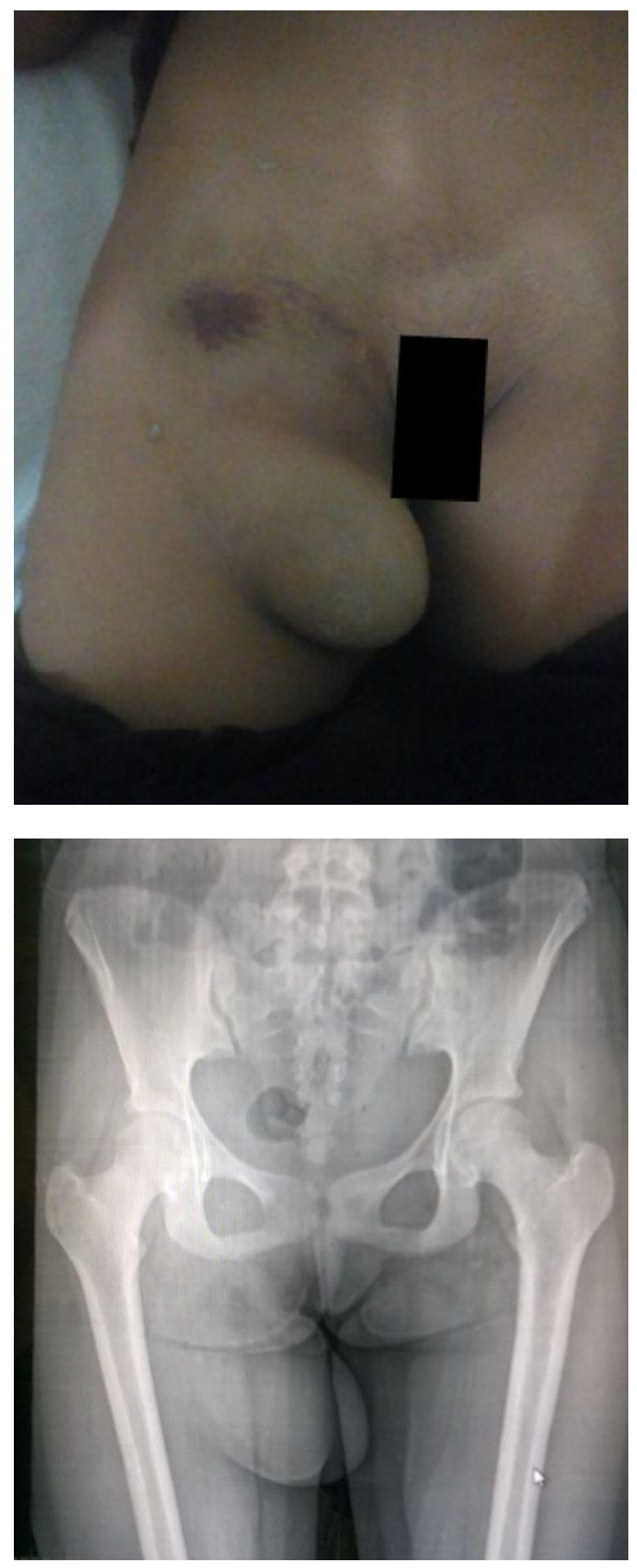


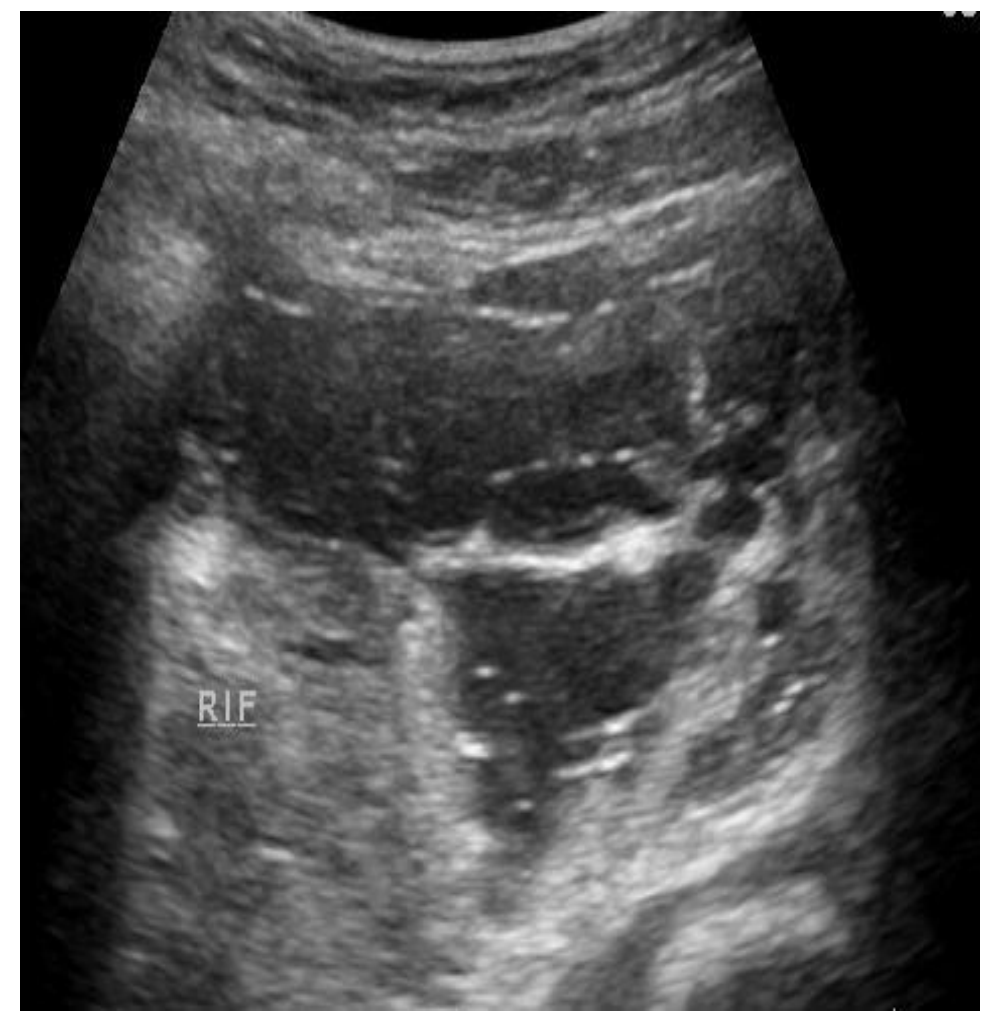

Image A right iliac fossa.

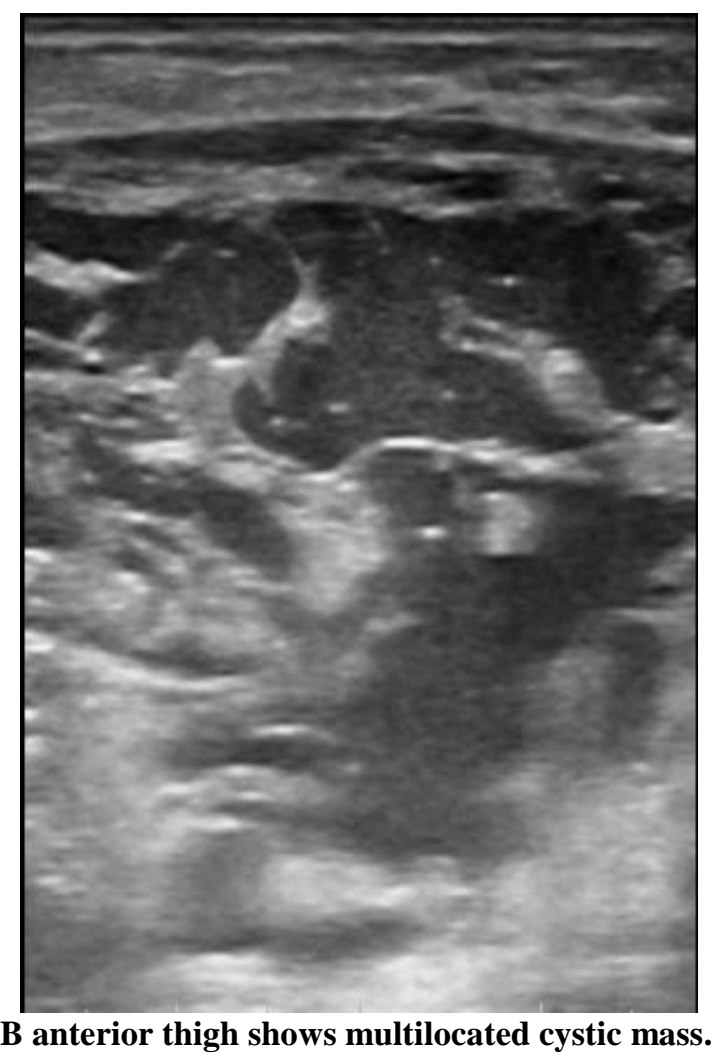




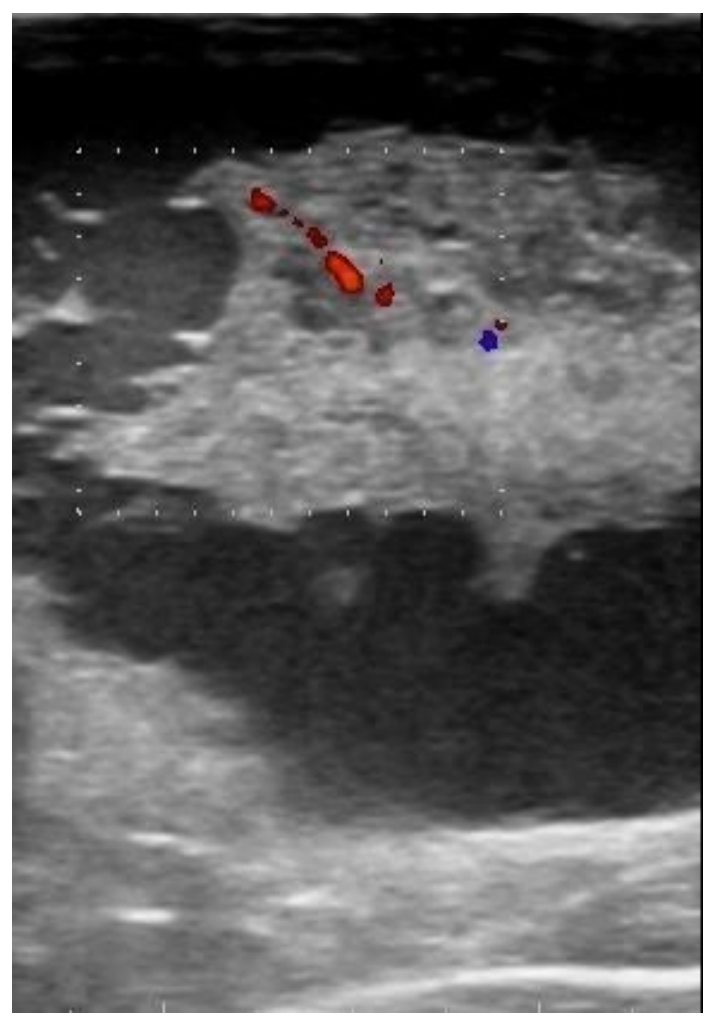

C colour dopler no vassucularity on solid mass.

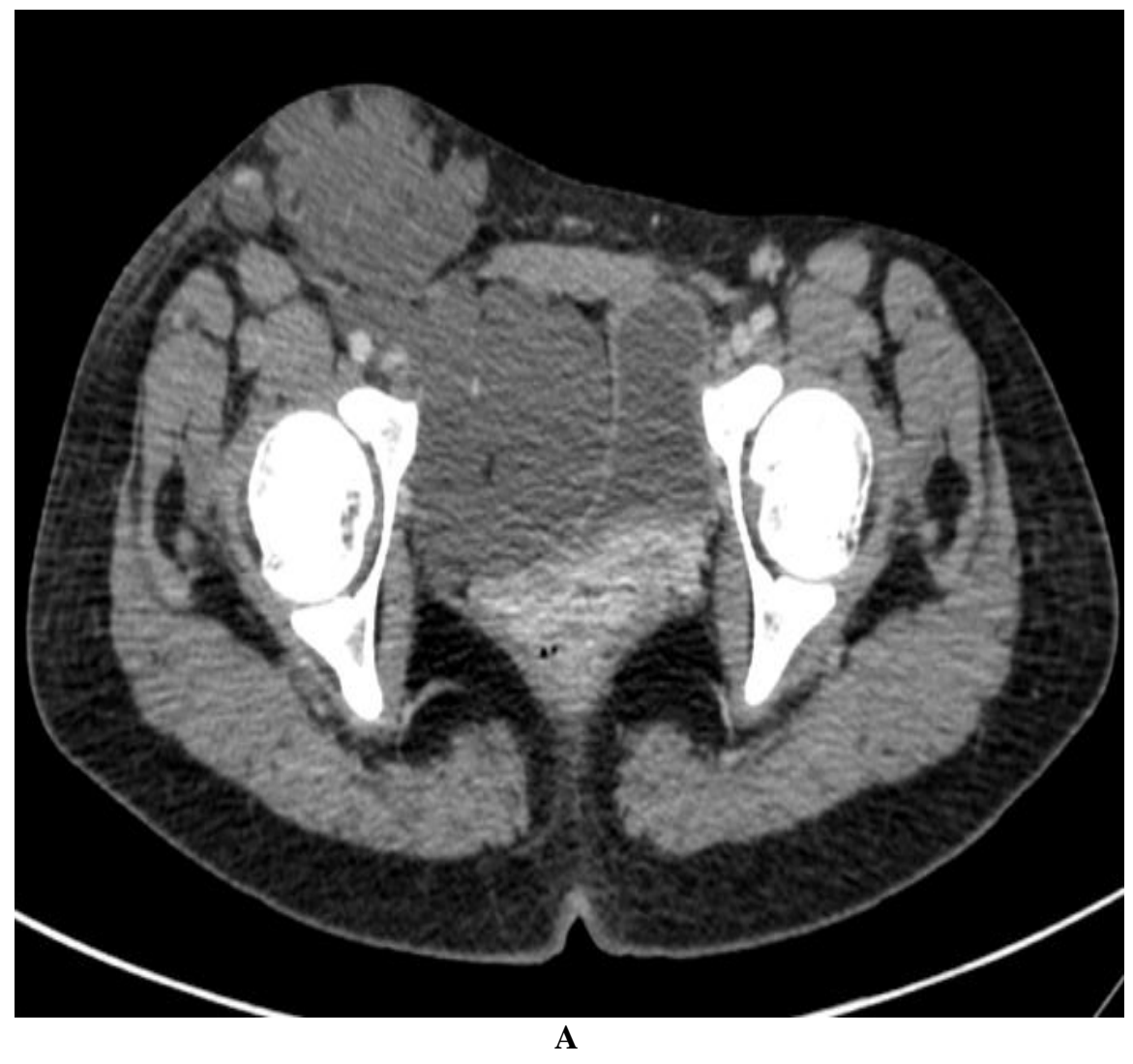




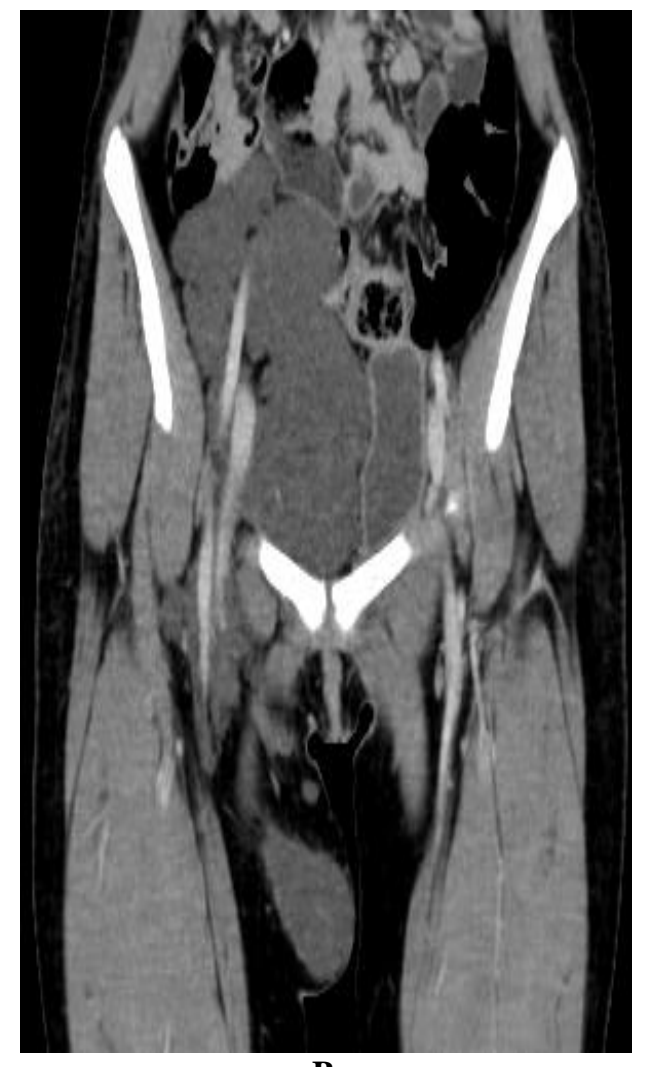

B

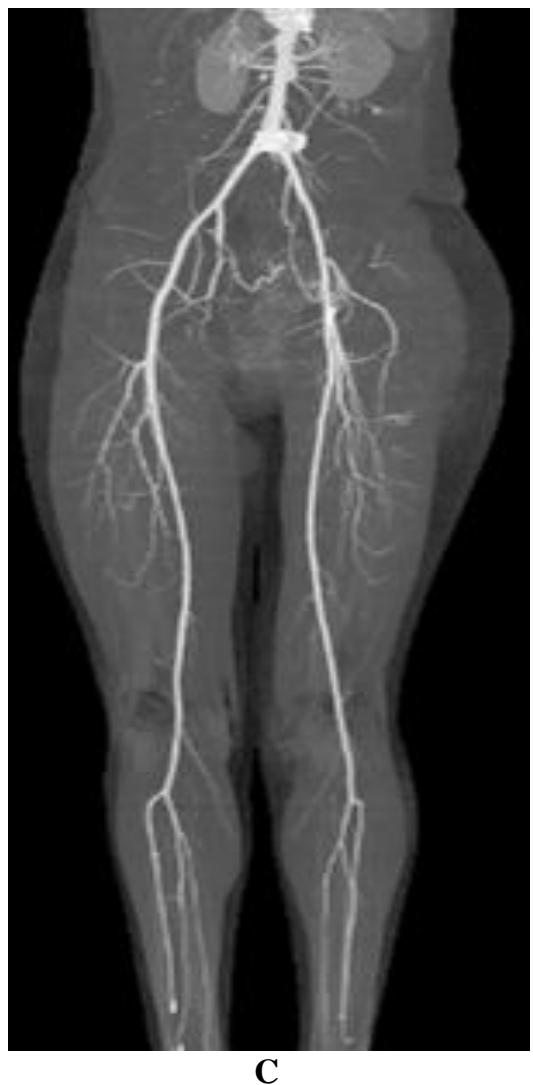


CECT pelvis axial [A] , coronal section [B] \& CT Angiography [C] showing A large ill-defined hypodense lobulated mass in right side of pelvis, extending into the medial portion of right upper thigh . The mass does not show significant contrast enhancement on post contrast studies. It is encasing the right common iliac, external iliac arteries and closely abutting the right common and proximal portion of superficial femoral artery, however no vascular invasion is seen. Mass effect on right wall of urinary bladder and uterus is seen which is displaced towards left side.possibility lymphangioma or Benign / low grade mass.

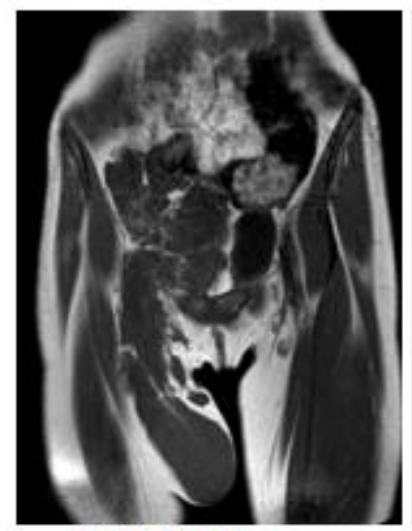

T1W image

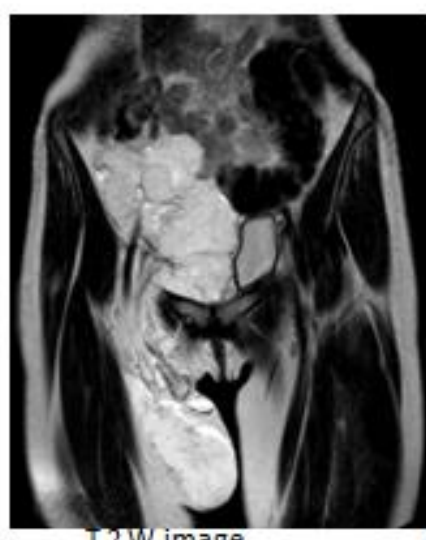

T2W image

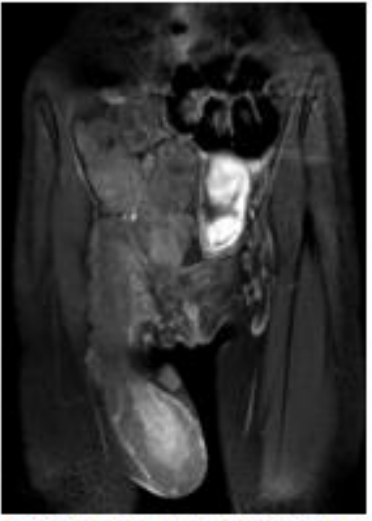

T $1 \mathrm{~W}+$ contrast STIR image

MRI imaging revealed well defined large lesion in anteromedial compartment of $r$ thigh and in pelvis. The lesion appears hypointense on T1 W image and hyperintense on T2W images.the lesion causing compression over Bladder with its left side displacement. The lesion shows peripheral as well as septal enhancement.The lesion encasing external iliac $\&$ femoral vessels.

Final diagnosis of a compressible multiloculated large cystic lesion with varying thickness septa was made lymphangioma complicated by infection with haemorrhage.
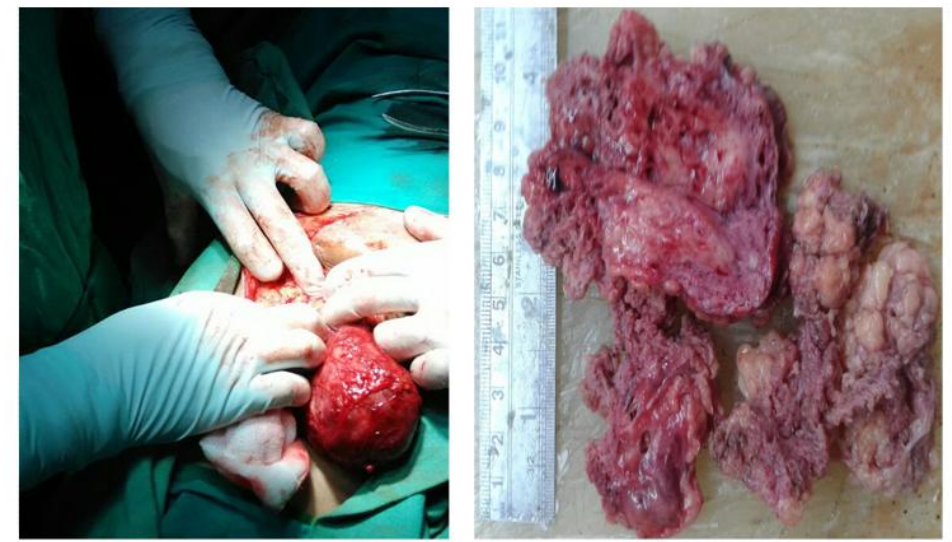

The lesion surgically resected and biopsy specimen send for histopsthogical examination and confirmed as cystic

\section{lymphangioma}

\section{Discussion:-}

Cystic lymphangioma or cystic hygroma is a low-flow vascular malformation, developing where the lymph sacs are separated from the venous drainage system. The most common location is the neck region (75\%), especially in the posterior triangle and in the back cervical cavity, but it can be also found in axillary region (20\%) and infrequently in the retroperitoneum, mesentery, omentum, colon, pelvis, groin, bone, skin, scrotum and spleen ${ }^{4}$ 
So far very few cases of classical congenital cystic hygroma [lymphangioma] of thigh have been reported. However few cases of traumatic cystic hygroma have also been reported in literature ${ }^{5}$

\section{Conclusion:-}

The Retroperitoneal cysts are very rare and most of the time they are discovered incidentally. The patients may be asymptomatic or present with abdominal pain, referred pain to the legs or weight loss. So Imaging may help to diagnose these lesions.

Funding: No funding sources

Conflict of interest: None declared

Ethical approval: The study was approved by the institutional ethics committee

\section{References:-}

1. Correia FM, Seabra B, Rego A, et al. Cystic lymphangioma of the mediastinum. J Bras Pneumol 2008;34:9824 [PubMed]

2. Khobta N, Tomasini P, Trousse D, et al. Solitary cystic mediastinal lymphangioma. Eur Respir Rev 2013;22:913 [PubMed]

3. Shaffer K, Rosado-de-Christenson ML, Patz EF, Jr, et al. Thoracic lymphangioma in adults: CT and MR imaging features. AJR Am J Roentgenol 1994;162:283-9 [PubMed]

4. Mohammadi A, Ghasemi-rad M, Abassi F. Asymptomatic lymphangioma involving the spleen and mediastinum in adults. Med Ultrason 2013;15:154-6 [PubMed]

5. Sinha M, Jane MJ, Watson SB. An unusual case of a large cystic swelling in thigh: Cystic lymphangioma in an adult. Eur J Plast Surg. 2009;32:103-106. doi: 10.1007/s00238-008-0283-6. [Cross Ref]. 